\title{
MiR-512-3p regulates malignant tumor behavior and multi-drug resistance in breast cancer cells via targeting Livin
}

\author{
W. J. DUAN ${ }^{1, \star}$, P. D. $\mathrm{BI}^{2}$, Y. MA ${ }^{1}$, N. Q. LIU' ${ }^{1}$ X. ZHEN ${ }^{3}$ \\ ${ }^{1}$ Department of Breast Surgery, The First Affiliated Hospital of Kunming Medical University, Kunming, China; ${ }^{2}$ Department of General Surgery, \\ the First Affiliated Hospital of Kunming Medical University, Kunming, China; ${ }^{3}$ Kunming Medical University Clinical Medicine, Kunming, China
}

*Correspondence: $1305185662 @ q q . c o m$

Received January 6, 2019 / Accepted July 9, 2019

\begin{abstract}
Breast cancer $(\mathrm{BCa})$ is one of the most lethal malignancies of female reproductive organs. Increasing evidence has revealed that miRNAs participate in both tumorigenesis and multi-drug resistance. MiR-512-3p, a small non-coding RNA (miRNA), was previously found to be upregulated in breast cancer cells. In this study, we first verified that miR-512-3p expression forced a significant reorganization of the tumor architecture, affecting important cellular processes involved in cell-cell contact, cell adhesion and cell motility. Accordingly, induction of miR-512-3p expression significantly enhanced chemosensitivity and decreased metastatic potential in BCa cells. Our study demonstrated that miR-512-3p directly targets the 3'UTR of Livin, thereby decreasing its expression in MCF-7 cells. MiR-512-3p overexpression significantly inhibited breast cancer cell growth and metastasis. Both miR-512-3p overexpression and Livin knockdown significantly increased the chemosensitivity of cancer cells. Epirubicin (EPB), gemcitabine (GCB) and docetaxel (TXT) had antitumor effects in vitro against human breast cancer cell lines, and miR-512-3p overexpression increased tumor sensitivity to these drugs. In addition, miR-512-3p overexpression significantly inhibited tumor growth in vivo. Collectively, our data suggest that miR-512-3p is a significant regulator of tumorigenesis and drug resistance in breast cancer and provides evidence that miR-512-3p may represent a promising target for breast cancer therapy.
\end{abstract}

Key words: breast cancer, multi-drug resistance, $m i R-512-3 p$, Livin, migration

Breast cancer $(\mathrm{BCa})$ remains one of the most common causes of cancer-related death worldwide and the second leading cause of tumor-related death among women [1]. Despite substantial improvements in chemotherapy, radiotherapy and surgical techniques for breast cancer over the past few decades, breast cancer patient prognosis is still not optimistic [2, 3]. BCa is also characterized by high incidence of drug resistance, leading to treatment failure and death in the majority of patients who experience distant metastasis [4]. Multiple mechanisms involved in drug resistance have been proven to occur during breast cancer treatment, including somatic mutations or epigenetic modifications within drug targets, dysregulated apoptosis or survival, adapted signaling pathways or metabolic reprogramming, as well as issues with the drug reaching its targets or drug transport modification within the tumor microenvironment [5-8]. Nevertheless, the underlying molecular mechanisms dictating tumorigenesis, tumor progression, metastasis and chemoresistance remain unclear. Therefore, a better understanding of the targeted molecules involved in breast cancer is needed to identify new therapeutic strategies for effective and sensitive of breast cancer-interventions.

MicroRNAs (miRNAs) are a class of endogenous, small non-coding RNAs 20-25 nucleotides in length capable of regulating gene expression [9]. MiRNAs, specifically bind to the 3' untranslated region of their target genes mRNA, negatively regulating gene expression at the post-transcriptional level [10]. Previous studies suggest that miRNAmediated downregulation of gene expression is involved in multi-drug resistance [11-13]. It has been reported that inhibition of c-FLIP by miR-512-3p might contribute to taxol-induced apoptosis in hepatocellular carcinoma cells [14]. MiR-512-3p inhibits tumor cell adhesion, migration and invasion by regulating the RAC1 activity via DOCK3 in non-small cell lung cancer [15]. However, the role of miR-512-3p in breast cancer remains largely unexplored.

Livin is a member of the inhibitor of apoptosis (IAP) family and the baculovirol IAP repeat-containing 7 (BIRC7) gene that encodes Livin is located at chromosomal position 20p13.3 [16]. Several researchers have observed that Livin 
plays a role in tumorigenesis [17]. Overexpression of Livin may inhibit cellular apoptosis induced by several anticancer agents and is associated with drug resistance in cancer cells $[18,19]$.

In the present study, we demonstrated that miR-512-3p inhibits Livin expression via direct binding to the Livin 3'UTR. These findings imply that inhibition of Livin by miR-512-3p might contribute to drug induced apoptosis in breast cancer cells. Experiments confirmed that increased miR-512-3p expression inhibits cell migration and invasion of breast cancer cells by downregulating Livin expression, further elucidating the molecular mechanisms involved in breast cancer progression and suggesting novel treatment targets.

\section{Patients and methods}

Patient characteristics and clinicopathological features. Paired breast cancer tissues and adjacent normal tissues surgically resected for qRT-PCR were collected from 10 primary breast cancer patients during surgery at the First Affiliated Hospital of Kunming Medical University. Surgically removed tissues were quickly frozen in liquid nitrogen until analysis. The research protocol was approved by the Ethics Committee of the First Affiliated Hospital of Kunming Medical University. All study participants provided written informed consent. All experiments rigorously followed the Declaration of Helsinki principles.

Cell culture and transfection. Human breast cancer MCF-7 and T47D cells were cultured in RPMI-1640 media (Thermo Fisher Scientific, USA) supplemented with 10\% fetal bovine serum (Sigma-Aldrich; Merck KGaA, Germany) at $37^{\circ} \mathrm{C}$ in a humidified incubator with $5 \% \mathrm{CO}_{2}$. MiR-512-3p mimics, inhibitor and scrambled negative control were purchased from RiboBio Co., Ltd. (Guangzhou, China). Cells were seeded into 6-well plates and incubated overnight, followed by transient transfection with miR-512-3p mimics, miR-negative control mimics (miR-Ctrl), miR-512-3p inhibitor and miR-negative control inhibitor (anti-miR-Ctrl) using Lipofectamine 2000 (Invitrogen) according to the manufacturer's instructions. Gemcitabine, Epirubicin and Docetaxel were purchased from Sigma.

Western blot. Proteins in cell lysates were separated with SDS-PAGE and then transferred to nitrocellulose membrane (Millipore). Primary antibodies included Livin (cat. no. ab97350, 1:1500; Abcam, UK), tubulin (cat. no. sc-222377, 1:1000; Santa Cruz Biotechnology, Inc.), cleaved-caspase3 (cat. no. ab2302, 1:1000; Abcam, UK.), and GAPDH (cat. no. sc-47724, 1:1000; Santa Cruz Biotechnology, Inc.). Secondary antibodies included IRDye-conjugated donkey anti-mouse or anti-rabbit IgG (Licor Biosciences) and membranes were visualized using the Odyssey Infrared Imaging System (Gene Company Limited). Quantification of expression levels of these proteins was performed using Quantity-One-Software 29.0 (Bio-Rad Laboratories, Inc., USA). Gray scale images were analyzed using ImageJ software.
Extraction of total RNA and RT-qPCR. Total RNA was extracted using Trizol (Invitrogen). cDNA was synthesized with M-MLV reverse transcriptase (Promega) and quantified by realtime qPCR using the Biosystems StepOne ${ }^{\mathrm{tm}}$ Real-Time PCR system and Fast SYBR Green Master Mix (Applied Biosystems), with GAPDH and U6 as internal control. PCR primers were designed using NCBI online software Primer-BLAST and synthesized by Invitrogen. PCR conditions were as follows: $94^{\circ} \mathrm{C}$ for $2 \mathrm{~min}$, followed by $94^{\circ} \mathrm{C}$ for $30 \mathrm{~s}, 60^{\circ} \mathrm{C}$ for $30 \mathrm{~s}$ and $72^{\circ} \mathrm{C}$ for $1 \mathrm{~min}$ for 30 cycles and $72^{\circ} \mathrm{C}$ for $10 \mathrm{~min}$. Primer sequences used were as follows: U6, forward 5'-GATTACAGCCGAACGTGTAGGAA-3'; reverse 5'-AGCTTGATCGTTTCTCTGGCCACC-3'; GAPDH, forward 5'-TCCAGAGTGCAAGGCTTCAG-3'; reverse 5'-ACAGCACGCAGTAGCAGTA-3'; miR-512-3p, forward 5'-CGGCGGCACTCAGCCTTGAGGG-3'; reverse 5'-GTGCAGGGTCCGAGGT-3'; Livin, forward 5'-GAGCCAGTGTTCCCTCCAT-3'; reverse 5'-GCACGGCACAAAGACGAT-3'.

Cytotoxicity assay. Cytotoxicity of gene transfection was determined using the Cell Counting Kit-8 (CCK-8) assay. Cells were seeded in 96-well plates in $100 \mu \mathrm{l}$ RPMI-1640 media supplemented with $10 \%$ FBS at the density of $5 \times 10^{4}$ cells/well. Chemotherapeutic agents were then added into normal growth medium supplemented with FBS. After $48 \mathrm{~h}$ incubation, $10 \mu \mathrm{l}$ CCK- 8 was added and culture continued for another $1 \mathrm{~h}$ in a humidified atmosphere containing 5\% $\mathrm{CO}_{2}$. Absorbance was measured at $450 \mathrm{~nm}$ using a microplate reader (Bio-Tech Company). Relative drug resistance fold of was analyzed by comparison with the IC50.

Scratch-healing migration assay. Approximately $5 \times 10^{4}$ cells were seeded in 6-well plates and cultured to $70-80 \%$ confluence. Wounds were established using a $20 \mu \mathrm{l}$ pipette tip, and cells were allowed $24 \mathrm{~h}$ to migrate into the wounds. To assess migration of cells across the artificial wound, a total of five optical fields were randomly selected. Images were acquired using a microscope (Zeiss, Axiovert 200, Germany).

Cell invasion assay. Cells in each group were digested using $0.25 \%$ trypsin and centrifuged before diluting with RPMI-1640 culture medium to $5 \times 10^{8}$ cells/l. Diluted MCF-7 cells were seeded into the upper chamber of Transwell chambers, and $0.6 \mathrm{ml}$ RPMI-1640 media containing 10\% FBS was added into the lower chamber before being cultured in an incubator at $37^{\circ} \mathrm{C}$ and $5 \% \mathrm{CO}_{2}$ for $24 \mathrm{~h}$. After the experiment, $4 \%$ paraformaldehyde was used to fix cells, and cotton swabs were used to wipe cells that did not penetrate into the lower chamber. The number of cells penetrating the Matrigel was recorded as the number of invasive cells.

Apoptosis assay. Cells transfected with miR-512-3p mimics, or NC were harvested and collected at $48 \mathrm{~h}$. After double staining with Annexin V-FITC and PI using the apoptosis detection kit (BD Biosciences) according to the manufacturer's protocol, cells were analyzed using a flow cytometer (FACScan) equipped with CellQuest software (both from BD Biosciences). Cells were discriminated into 
viable cells, dead cells, early apoptotic cells, and apoptotic cells, and then the relative ratio of early apoptotic cells was compared to control transfectants from each experiment.

MiRNA target prediction. MiRNAs that may target Livin were identified using algorithms from TargetScan (http:// genes.mit.edu/targetscan/), PicTar (http://pictar.mdc-berlin. de/), and miRanda (http:// cbio.mskcc.org/cgi-bin/mirnaviewer/mirnaviewer.pl).

Luciferase reporter assay. The 3' untranslated region (UTR) of the human Livin gene that was predicted to interact with miR-512-3p was synthesized and inserted into pMIRREPORT (Ambion), yielding pMIR-REPORT Livin. Cells were transfected with pMIR-REPORT vectors containing the 3'UTR variants and miR-512-3p mimics for $24 \mathrm{~h}$. Luciferase values were determined using the Dual-Luciferase Reporter Assay System (Promega).

Chromatin immunoprecipitation (ChIP). ChIP assays were carried out following the standard protocol. Briefly, MCF7 cells were cross-linked with $1 \%$ of formaldehyde (Sigma) for $15 \mathrm{~min}$ at room temperature with gentle shaking. Cells were harvested with cell scraper and chromatin was fragmentized to average $300 \mathrm{bp}$ in length with sonicator. Diluted whole cell sonicates were incubated with anti-Ago2 antibodies with normal serum IgG as controls. After protein

A

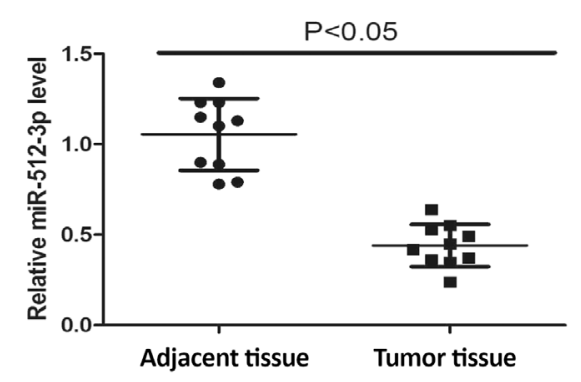

C

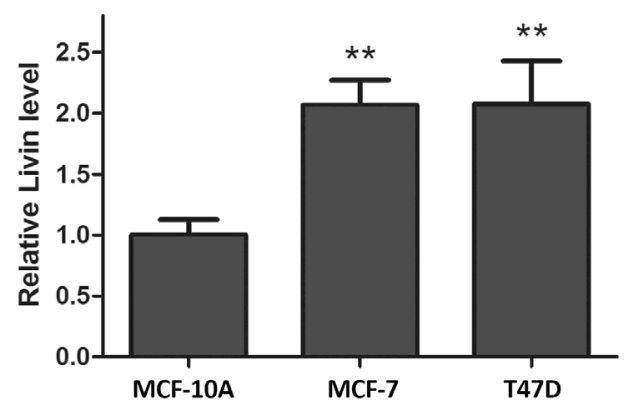

A beads (Millipore, 17-295) binding, washing and eluting, ChIP products were purified with phenol/chloroform and measured by real-time qPCR. Primer sequences used were as follows: forward 5'-TGTTTCCTCACTTACGC-3'; reverse 5'-TTCCATTTCAGGTTCTC-3'.

In vivo tumorigenicity assay. Male $\mathrm{BALB} / \mathrm{c}$ nude mice (4-5 weeks of age) were purchased from Beijing HFK Bioscience Co., Ltd. Mice were housed in a pathogen-free animal facility and randomly assigned to the control or experimental group (five mice per group). For each cell line, $2 \times 10^{6}$ cells were resuspended in $200 \mu \mathrm{l}$ medium and subcutaneously injected into nude mice. Tumor formation was monitored every three or four days by measuring the largest and the smallest diameter of formed tumors. Upon euthanasia, tumors were dissected and their wet weights were recorded. All experiments and animal care practices were reviewed and approved by the Ethics Committee of Animal Experiments of the First Affiliated Hospital of Kunming Medical University.

Statistical analysis. All statistical analyses were performed using SPSS 17.0 (SPSS, Chicago, USA) using either one-sample t-test or one-way ANOVA analysis. All data are presented as the mean \pm S.E.M. p-values less than 0.05 are indicated by ${ }^{*}$, and values less than 0.01 are indicated by ${ }^{*}$.

B

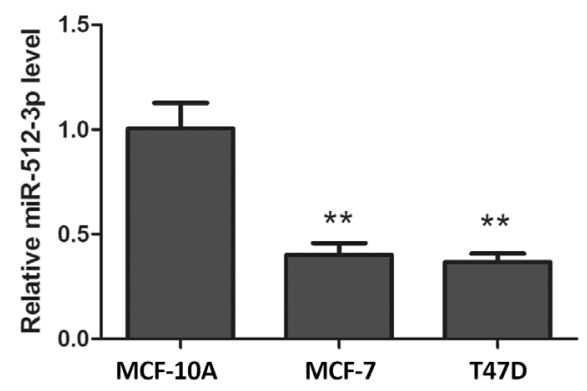

D

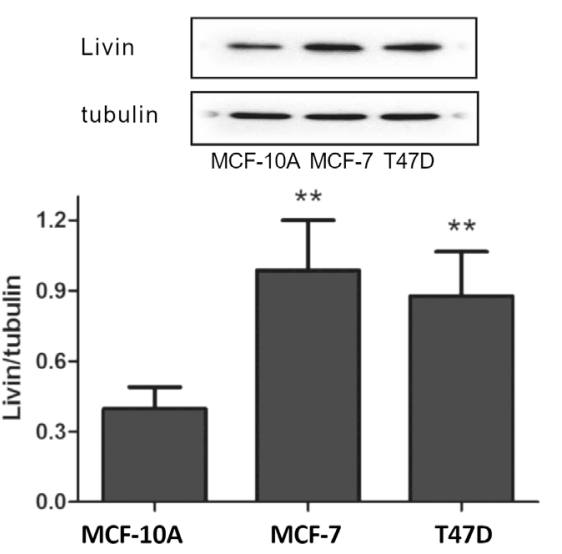

Figure 1. MiR-512-3p and Livin play an important role in the development of breast cancer. A) qRT-PCR was performed to detect expression of miR512-3p in 10 pairs of breast cancer tissues and adjacent non-cancerous tissues. B) MiR-512-3p expression in two breast cancer cell lines (MCF-7, T47D) and normal breast epithelial cells (MCF-10A) was detected by real-time PCR. C and D) Livin expression in two breast cancer cell lines (MCF-7, T47D) and normal breast epithelial cells (MCF-10A) was detected by western blot and real-time PCR. GAPDH and U6 was used as internal controls. Error bars represent the mean \pm SEM of at least three independent experiments. n.s.: not significant, ${ }^{*} \mathrm{p}<0.05,{ }^{*} \mathrm{p}<0.01$ vs. control group. 


\section{Results}

miR-512-3p and Livin play an important role in breast cancer development. MiRNAs influence a variety of physiological and pathological processes by regulating expression of the target genes, which is implicated in both tumor progression and resistance to treatment [20]. qRT-PCR analysis was performed in 10 pairs of breast cancer samples and adjacent non-cancerous tissues. The results demonstrated that miR-512-3p was highly expressed in adjacent non-cancerous tissues compared to cancer samples (Figure 1A). Furthermore, miR-512-3p expression was much lower in breast cancer cells than in normal epithelial cells in mRNA levels (Figure 1B). Several studies have observed that Livin plays a role in tumorigenesis. To investigate the role of Livin in the development of breast cancer, qRT-PCR and western blot were performed in analysis breast cancer cells and normal epithelial cells. The results showed that Livin was highly expressed in breast cancer cells compared to normal epithelial cells at both mRNA and protein levels (Figures 1C and D). These results indicate that miR-512-3p and Livin play an important role in the development of breast cancer.

miR-512-3p directly targets Livin in human breast cancer cells. We next examined the effect of miR-512-3p on endogenous Livin expression. Figure 2A shows the conserved target sites for miR-512-3p in the 3'UTR of Livin. To test this, we sub-cloned the Livin 3'UTR downstream of the luciferase gene. Co-transfection of cells with pMIR-Livin plus the miR-512-3p mimics decreased luciferase activity. To further prove that miR-512-3p suppresses Livin by binding to the Livin 3'UTR, the Livin 3'UTR was mutated and sub-cloned downstream of the luciferase gene. As we expected, luciferase activity was unchanged by the overexpression of miR-512-3p (Figure 2B). To validate whether Livin was a functional target of miR-512-3p in breast cancer, we immunoprecipitated Argonaute 2 (Ago2), an important element of RNA-induced silencing complex (RISC). The results showed that Ago2 showed increased association with the Livin 3'UTR region after miR-512-3p mimics transfection (Figure 2C). Next, qRT-PCR and western blot analysis were used to determine expression of Livin regulated by miR-512-3p in MCF-7 and T47D cells. Our results revealed that miR-512-3p mimics significantly inhibited expression of Livin (Figures $2 \mathrm{D}$ and F), whereas silencing miR-512-3p significantly increased Livin expression (Figures 2E and G). Our date demonstrated that negative post-transcriptional regulation of miR-512-3p on Livin was dependent on miR-512-3p target sites in the Livin 3'UTR region.

miR-512-3p inhibits cell proliferation, migration and invasion of breast cancer cells. To characterize the function of miR-512-3p in breast cancer, we treated MCF-7 cells with $50 \mathrm{nM}$ miR-512-3p mimics to investigate its effect on in vitro proliferation. MiR-512-3p mimics were transfected into MCF-7 cells to overexpress miR-512-3p. As illustrated in Figure 3A, expression of miR-512-3p was significantly enhanced in cells transfected with miR-512-3p mimics. Our results showed that miR-512-3p inhibits proliferation in MCF-7 cells. Cells proliferation was further inhibited upon co-treatment with epirubicin, gemcitabine and docetaxel (Figure 3B). Similarly, in vitro migration assays revealed that overexpression of miR-512-3p inhibited the migration of MCF-7 cells. Cells migration was further inhibited upon co-treatment with EPB, GCB and TXT (Figures 3C and D). Next, in vitro invasion assays demonstrated that the overexpression of miR-512-3p inhibits the invasion ability of MCF-7 cells. Co-treatment of MCF-7 cells with EPB, GCB or TXT and miR-512-3p mimics further inhibited invading cells (Figures 3E and F). As shown in Figure 3G and H, in the miR-512-3p mimics group, apoptosis rates were markedly higher compared to the NC group. In addition, apoptosis rates were further increased upon co-treatment with EPB, GCB and TXT. To further define the apoptotic pathway, we measured expression of cleaved caspase- 3 in MCF-7 cells. Data showed that miR-512-3p increased expression of cleaved caspase-3, and levels were further increased when co-treated with EPB, GCB and TXT (Figures 3I and J). Our date demonstrated that miR-512-3p inhibits cell proliferation, migration and invasion of breast cancer cells.

miR-512-3p modulates tumorigenesis and drug resistance through Livin in breast cancer cells. Considering that miR-512-3p is dysregulated in MCF-7 cells, we investigated the effect of miR-512-3p on drug sensitivity of these cells. CCK-8 assay showed that MCF-7 cells with enforced miR-512-3p expression exhibited increased sensitivity to $\mathrm{EPB}, \mathrm{GCB}$ and TXT. We further investigated the functional role of Livin in MCF-7 cells. CCK-8 assay showed that enforced Livin expression significantly enhanced drug resistance. The following results also confirmed that both miR-512-3p overexpression and increased Livin significantly decrease drug sensitivity in MCF-7 cells (Figure 4A). Flow cytometry data on apoptosis were evaluated to analyze the effect of miR-512-3p on drug sensitivity. Exposure of MCF-7 cells to EPB, GCB and TXT resulted in increased apoptosis levels. Treatment with miR-512-3p mimics enhanced this effect upon co-treatment. In the Livin overexpression group, apoptosis was significantly reduced compared to drug treatment and miR-512-3p mimics co-treated groups (Figures 4B and C). Our data demonstrated that miR-512-3p modulates tumorigenesis and drug resistance through Livin in breast cancer cells.

miR-512-3p overexpression inhibits breast cancer growth in a nude mouse xenograft model. Next, we investigated whether overexpression of miR-512-3p in breast cancer cells could reduce tumor growth in vivo. As shown in Figure $5 \mathrm{~A}$, tumors formed from miR-512-3p mimics transfected MCF-7 cells grew significantly more slowly than those from controls. MiR-512-3p mimics treated tumors grew slower than did control tumors with respect to tumor weight (Figures 5B and C). These data suggest that miR-512-3p overexpression inhibits the development of breast cancer. 
A
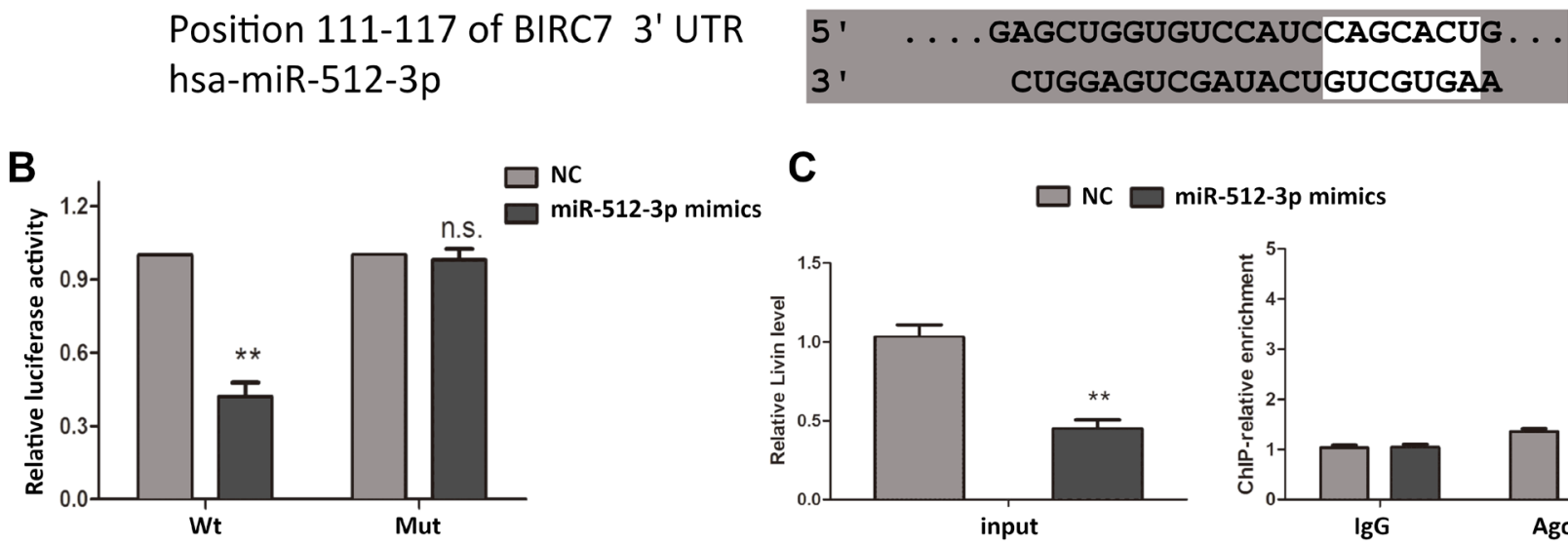

C iR-512-3p mimics
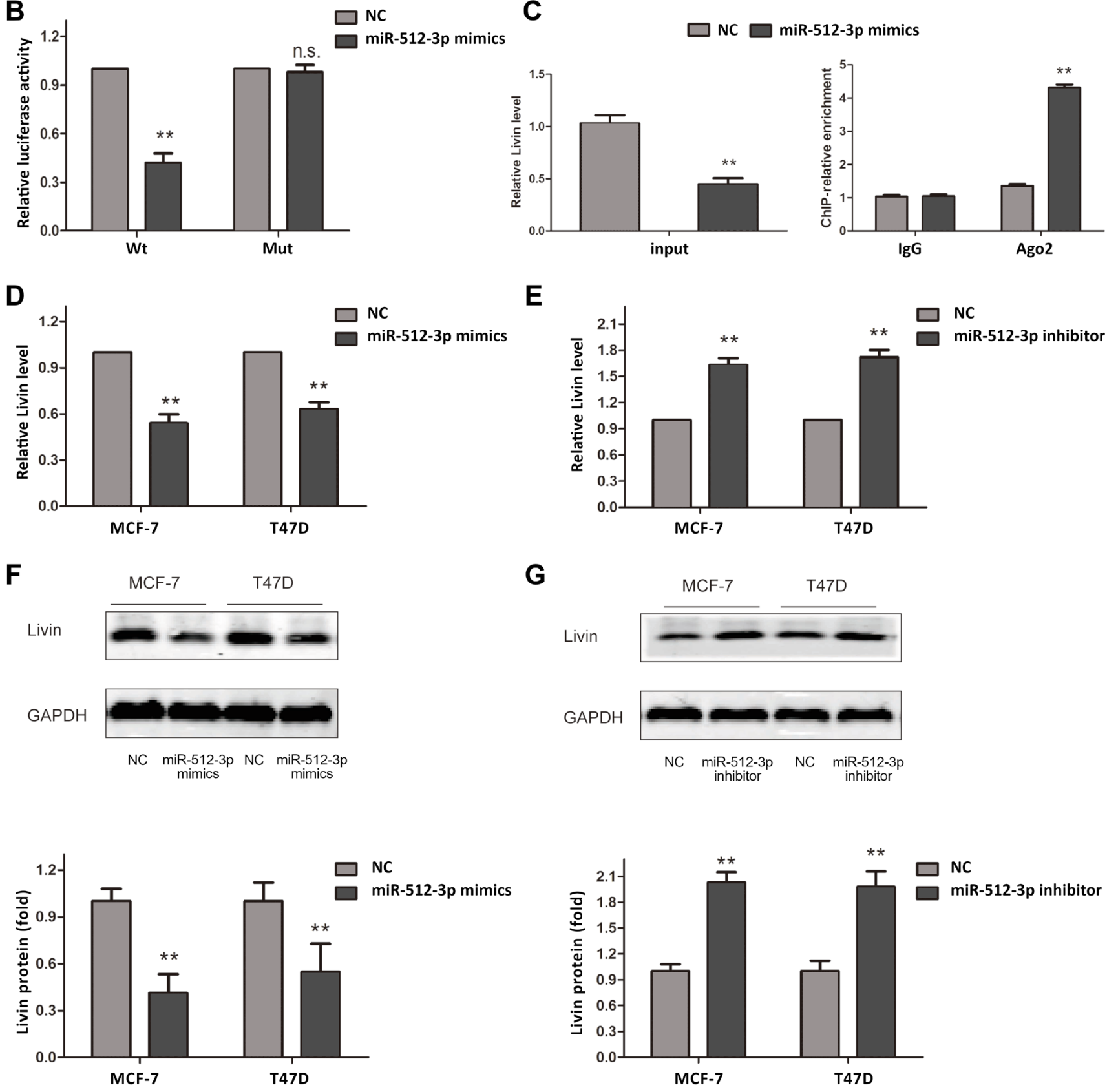

Figure 2. MiR-512-3p directly targets Livin in human breast cancer cells. A) Bioinformatics analysis of possible binding sites between miR-512-3p and the 3'UTR of Livin. B) Luciferase assay in MCF-7 cells co-transfected with miR-512-3p mimics and a luciferase reporter containing the Livin 3'UTR (Wt) or a mutant (Mut). C) ChIP was performed with Ago2 antibodies and ChIP products were quantitatively analyzed using qPCR. D) Overexpression of miR-512-3p inhibits expression of Livin at the mRNA level in MCF-7 and T47D cells. E) Downregulated expression of miR-512-3p increased expression of Livin at the mRNA level in MCF-7 and T47D cells. F and G) Western blot showing Livin protein levels in MCF-7 and T47D cells in response to transfection with NC-mimics, miR-512-3p mimics, NC-inhibitor and miR-512-3p inhibitor. GAPDH was used as the endogenous control. Error bars represent the mean \pm SEM of at least three independent experiments. N.S.: not significant, ${ }^{*} \mathrm{p}<0.05,{ }^{* *} \mathrm{p}<0.01$ vs. control group. 

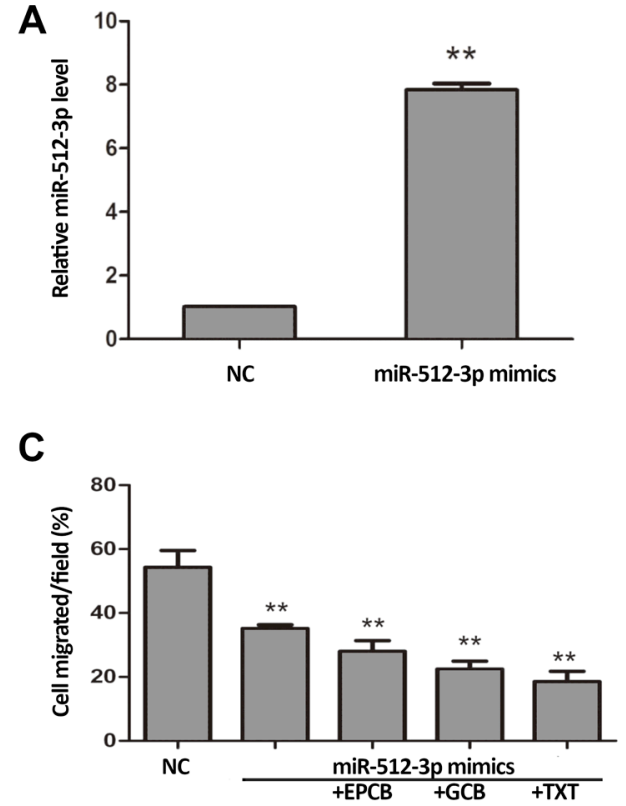

E

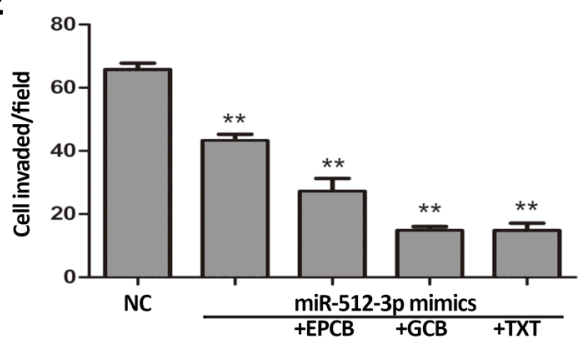

G

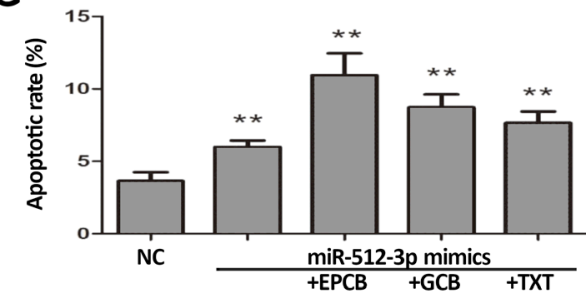

I

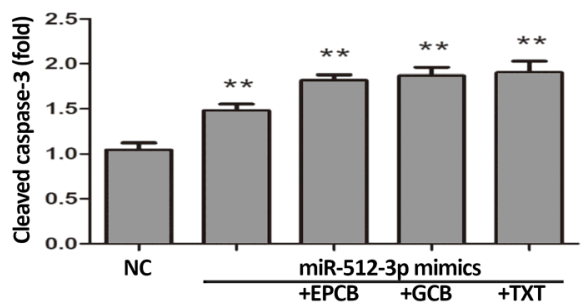

B

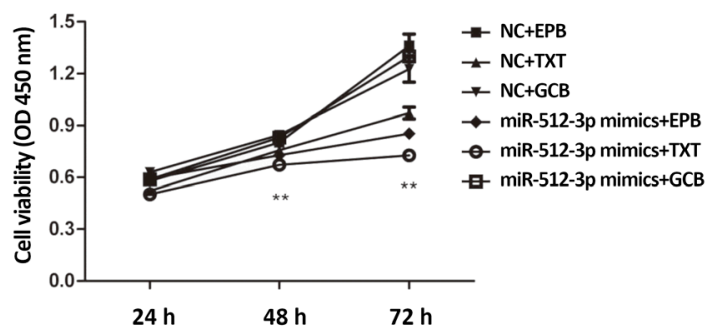

D NC

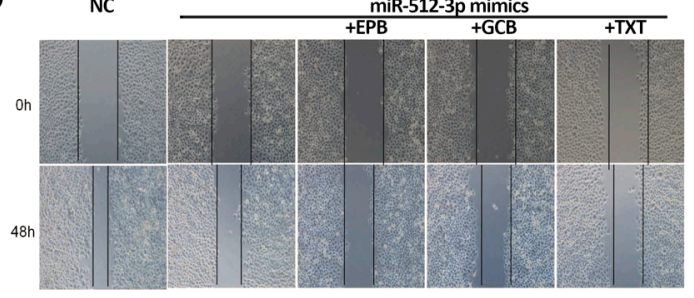

$\mathbf{F}$

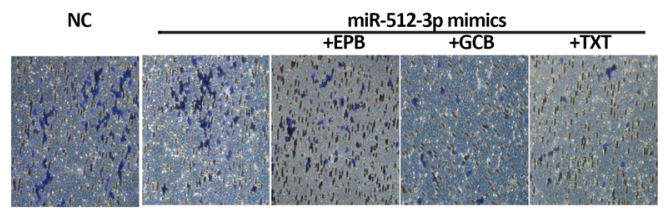

H

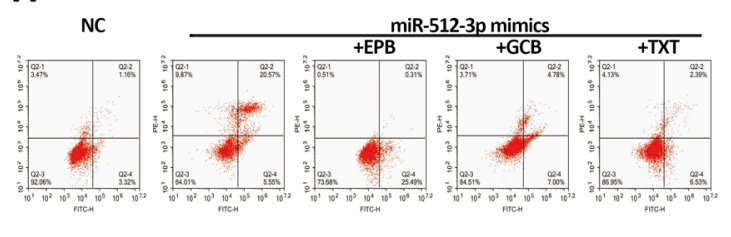

$J$

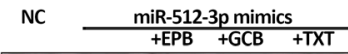

Procapase-3

Cleaved capase-3

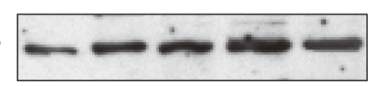

GAPDH

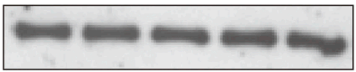

Figure 3. MiR-512-3p inhibits cell proliferation, migration and invasion of breast cancer cells. Cells were treated with $35 \mathrm{mg} / \mathrm{ml}$ of EPB, $5 \mathrm{mg} / \mathrm{ml}$ of GCB and $25 \mathrm{mg} / \mathrm{ml}$ of TXT in combination with transfection of $50 \mathrm{nM}$ miR-512-3p mimics as indicated. A) Overexpression of miR-512-3p by transfection with miR-512-3p mimics in MCF-7 cells. B) CCK-8 assay was performed to analyze the effect of miR-512-3p on cell proliferation in MCF-7 cells. C) Results show quantitative analysis of cell migration rates. D) Results of scratch wound healing experiments show parallel migration of MCF-7 cells. E) Results show quantitative analysis of cell invasion numbers. F) Results of Transwell experiments show transmembrane invasion of MCF-7 cells. G) Results show quantitative analysis of cell apoptosis levels. H) Annexin V-FITC/PI staining of cells. I and J) Western blot showing caspase-3 protein levels in MCF-7 cells. Error bars represent the mean \pm SEM of at least three independent experiments. N.S.: not significant, ${ }^{\star} p<0.05,{ }^{* *} \mathbf{p}<0.01$ vs. control group. 
A

MCF-7

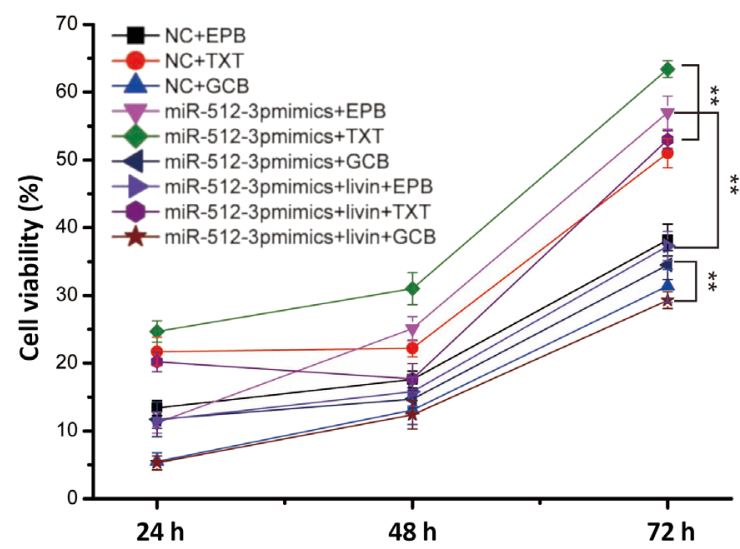

B
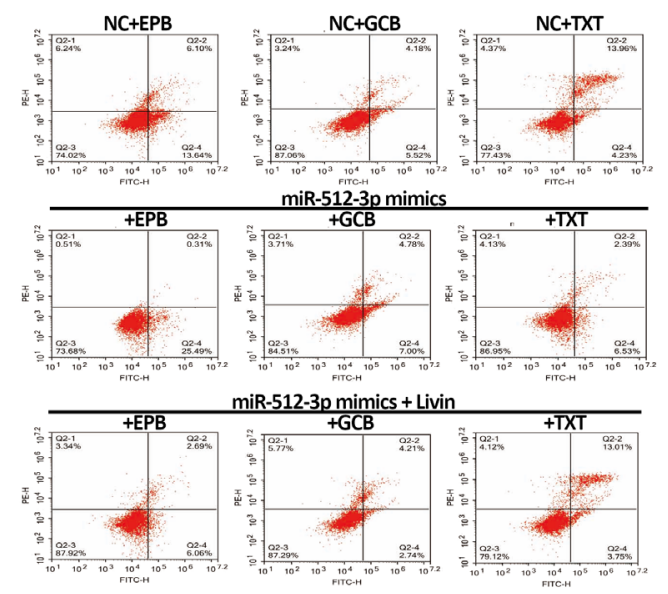

C

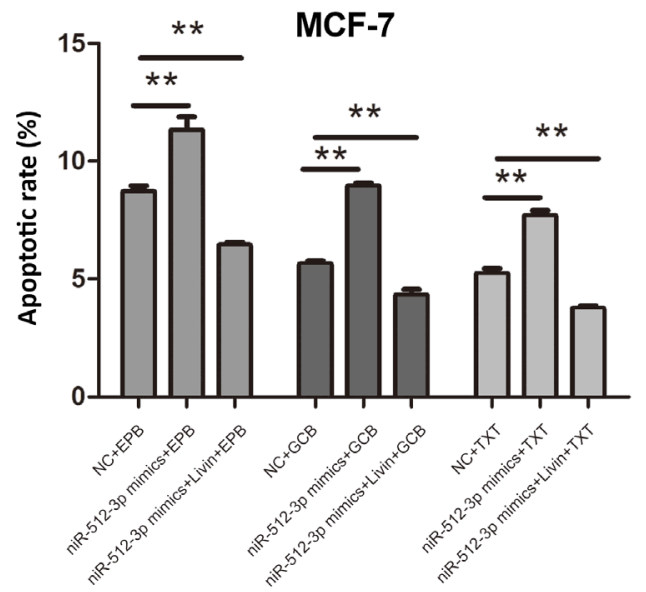

Figure 4. MiR-512-3p modulates tumorigenesis and drug resistance through Livin in breast cancer cells. MCF-7 cells were treated with 50 nM miR-512-3p mimics and pcDNA-3.1-Livin or co-treatment with 35 $\mathrm{mg} / \mathrm{ml}$ of EPB, $5 \mathrm{mg} / \mathrm{ml}$ of GCB and $25 \mathrm{mg} / \mathrm{ml}$ of TXT. A) CCK8 assay was performed to analyze the effect of miR-512-3p on drug resistance in MCF-7 cells. B) Annexin V-FITC/PI staining of cells. C) Results show quantitative analysis of cell apoptosis levels. Error bars represent the mean \pm SEM of at least three independent experiments. N.S.: not significant, ${ }^{*} \mathrm{p}<0.05,{ }^{* *} \mathrm{p}<0.01$ vs. control group.
A

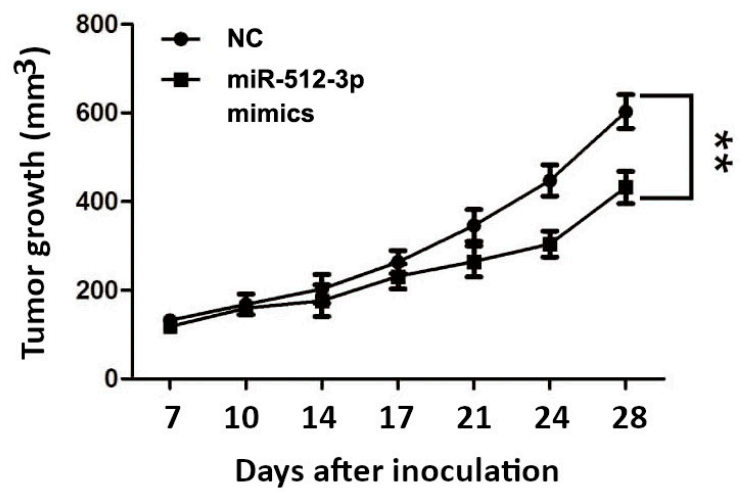

B
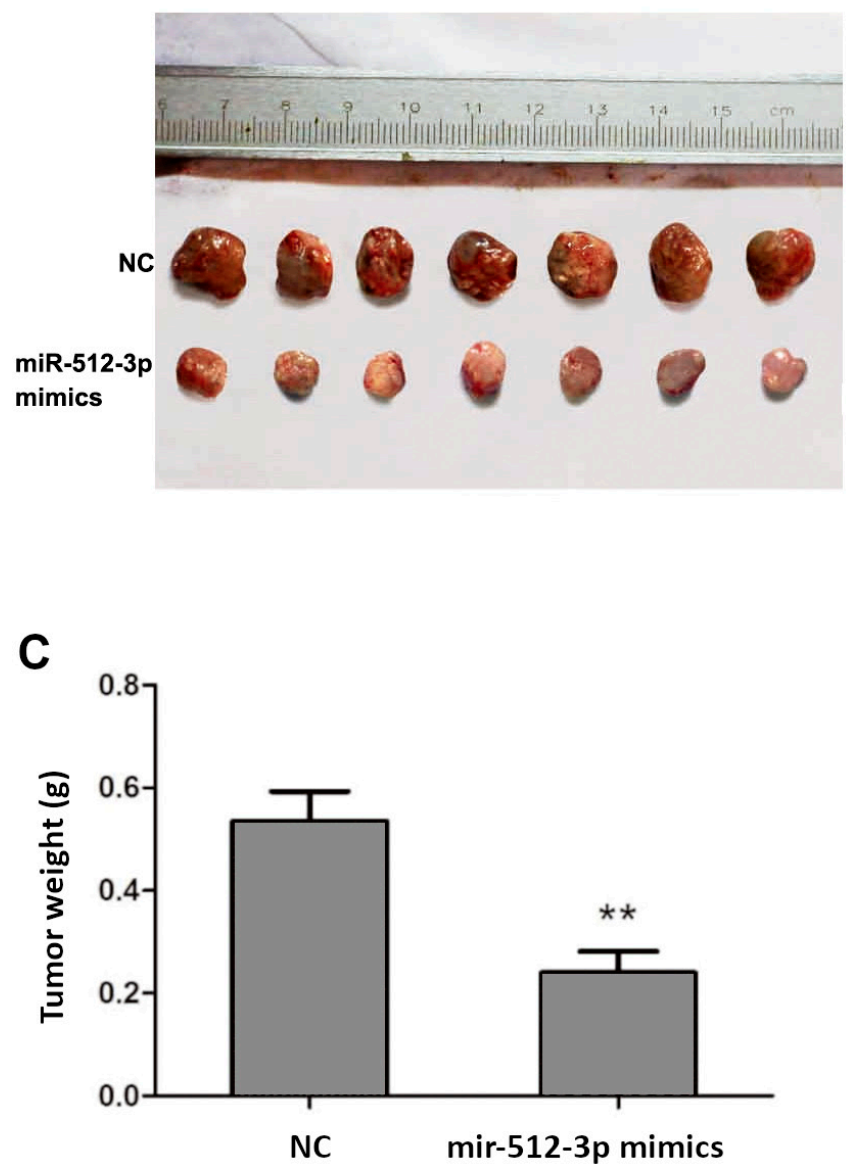

Figure 5. MiR-512-3p overexpression inhibits breast cancer growth in a nude mouse xenograft model. A) Tumor volume was calculated twice weekly. B) Images of tumors derived from NC and miR-512-3p mimics in nude mice. C) Tumor weights. Error bars represent the mean \pm SEM of at least three independent experiments. N.S.: not significant, ${ }^{*} p<0.05$, ${ }^{* *} \mathbf{p}<0.01$ vs. control group. 


\section{Discussion}

It is generally accepted that development of breast cancer, like other cancers, involves multiple steps, including accumulation of genetic and epigenetic changes. In recent years, investigation of epigenetic biomarkers such as miRNAs has implicated that these molecules may represent enticing translational biomarker candidates in various cancers [21]. Investigation of cancer-specific miRNAs and their targets is necessary for further elucidation of their roles in tumor progression and drug resistance, and may be important for the design of novel therapeutic targets [22-24].

Tumor resistance to apoptosis is one of the most common phenomena that occurs in cancer. Evasion of apoptosis contributes to carcinogenesis, tumor progression and to therapeutic resistance [25]. Livin is involved in the negative regulation of apoptosis. Livin binds to the endogenous IAP antagonist SMAC as well as caspase-3, caspase-7 and caspase-9 [26-28]. Our study observed that in MCF-7 cells, overexpression Livin significantly decreased apoptosis and increased drug resistance, consistent with several published results. However, small molecules, such as miRNAs, directly aimed at mRNA of the targets, are rarely reported due to the lack of valuable data on Livin regulation.

Our data revealed that miR-512-3p and Livin are inversely correlated. Using PicTar and TargetScan databases, we found that miR-512-3p induces apoptosis, on the contrary to Livin function. Furthermore, we found that miR-512-3p overexpression inhibits Livin luciferase activity. These results indicated that miR-512-3p inhibits Livin expression by binding to its 3'UTR region.

Saito et al. found that miR-512-3p is silenced in gastric cancer cells [29]. Overexpression of miR-512-3p resulted in apoptosis of gastric cancer cells by inhibiting the oncogene Mcl-1, indicating for the first time that miR-512-3p promotes apoptosis. In agreement with this, our study indicated that overexpression of miR-512-3p increased EPB, GCB and TXT induced apoptosis by inhibiting Livin expression. We also found that miR-512-3p could inhibits cell proliferation, migration and invasion of breast cancer cells and inhibits tumor growth in vivo, suggesting that miR-512-3p plays a key role in the regulation of tumor progression and drug resistance. Based on these findings, we infer that Livin is a functional target gene of miR-512-3p modulating tumor progression and MDR in breast cancer cells.

In conclusion, our data suggest that miR-512-3p expression in breast cancer offers a potential therapeutic application to disrupt the development of breast cancer, by altering tumor growth, chemosensitivity and metastatic potential.

Acknowledgements: This work was funded by Applied Basic research on YunNan Application (Joint Project of KunMing Medical University)

\section{References}

[1] VERONESI U, BOYLE P, GOLDHIRSCH A, ORECCHIA R, VIALE G. Breast cancer. Lancet 2005; 365: 1727-1741. https://doi.org/10.1016/S0140-6736(05)66546-4

[2] FOSSATI R, CONFALONIERI C, TORRI V, GHISLANDI E, PENNA A et al. Cytotoxic and hormonal treatment for metastatic breast cancer: a systematic review of published randomized trials involving 31,510 women. J Clin Oncol 1998; 16: 3439-3460. https://doi.org/10.1200/ JCO.1998.16.10.3439

[3] KOUKOURAKIS G. Radiation therapy for early breast cancer. Clin Transl Oncol 2009; 11: 596-603. https://doi. org/10.1007/s12094-009-0410-2

[4] O'DRISCOLL L, CLYNES M. Biomarkers and multiple drug resistance in breast cancer. Curr Cancer Drug Targets 2006; 6: 365-384. https://doi.org/10.2174/156800906777723958

[5] WANG Z, WANG N, LIU P, CHEN Q, SITU H et al. MicroRNA-25 regulates chemoresistance-associated autophagy in breast cancer cells, a process modulated by the natural autophagy inducer isoliquiritigenin. Oncotarget 2014; 5: 7013-7026. https://doi.org/10.18632/oncotarget.2192

[6] HU H, LI S, CUI X, LV X, JIAO Y et al. The overexpression of hypomethylated miR-663 induces chemotherapy resistance in human breast cancer cells by targeting heparin sulfate proteoglycan 2 (HSPG2). J Biol Chem 2013; 288: 10973-10985. https://doi.org/10.1074/jbc.M112.434340

[7] GAO M, MIAO L, LIU M, LI C, YU C et al. miR-145 sensitizes breast cancer to doxorubicin by targeting multidrug resistance-associated protein-1. Oncotarget 2016; 7: 5971459726. https://doi.org/10.18632/oncotarget.10845

[8] MULRANEL, MCGEESF, GALLAGHER WM, O'CONNOR DP. miRNA dysregulation in breast cancer. Cancer Res 2013; 73: 6554-6562. https://doi.org/10.1158/0008-5472.CAN-131841

[9] CHEN CZ. MicroRNAs as oncogenes and tumor suppressors. N Engl J Med 2005; 353: 1768-1771. https://doi. org/10.1056/NEJMp058190

[10] PENNA E, ORSO F, TAVERNA D. miR-214 as a key hub that controls cancer networks: small player, multiple functions. J Invest Dermatol 2015; 135: 960-969. https://doi. org/10.1038/jid.2014.479

[11] CHEN GQ, ZHAO ZW, ZHOU HY, LIU YJ, YANG HJ. Systematic analysis of microRNA involved in resistance of the MCF-7 human breast cancer cell to doxorubicin. Med Oncol 2010; 27: 406-415. https://doi.org/10.1007/s12032-0099225-9

[12] MOROZEVICH GE, KOZLOVA NI, CHEGLAKOV IB, USHAKOVA NA, PREOBRAZHENSKAYA ME. Implication of alpha5betal integrin in invasion of drug-resistant MCF-7/ADR breast carcinoma cells: a role for MMP-2 collagenase. Biochemistry (Mosc) 2008; 73: 791-796. https://doi. org/10.1134/s0006297908070079

[13] POGRIBNY IP, FILKOWSKI JN, TRYNDYAK VP, GOLUBOV A, SHPYLEVA SI et al. Alterations of microRNAs and their targets are associated with acquired resistance of MCF-7 breast cancer cells to cisplatin. Int J Cancer 2010; 127: 1785-1794. https://doi.org/10.1002/ijc.25191 
[14] CHEN F, ZHU HH, ZHOU LF, WU SS, WANG J et al. Inhibition of c-FLIP expression by miR-512-3p contributes to taxol-induced apoptosis in hepatocellular carcinoma cells. Oncol Rep 2010; 23:1457-1462. https://doi.org/10.3892/ or_00000784

[15] ZHU X, GAO G, CHU K, YANG X, REN S et al. Inhibition of RAC1-GEF DOCK3 by miR-512-3p contributes to suppression of metastasis in non-small cell lung cancer. Int J Biochem Cell Biol 2015; 61: 103-114. https://doi.org/10.1016/j. biocel.2015.02.005

[16] CHEN X, WANG T, YANG D, WANG J, LI X et al. Expression of the IAP protein family acts cooperatively to predict prognosis in human bladder cancer patients. Oncol Lett 2013; 5: 1278-1284. https://doi.org/10.3892/ol.2013.1150

[17] LIU X, WANG A, GAO H, YUAN Z, JIAO Y. Expression and role of the inhibitor of apoptosis protein livin in chemotherapy, sensitivity of ovarian carcinoma. Int J Oncol 2012; 41: 1021-1028. https://doi.org/10.3892/ijo.2012.1540

[18] WANG X, JIAN X, JU S, NI H, ZHU J et al. Livin gene plays a role in drug resistance of colon cancer cells. Clin Biochem 2010; 43: 655-560. https://doi.org/10.1016/j.clinbiochem.2010.02.004

[19] DUBREZ-DALOZ L, DUPOUX A, CARTIER J. IAPs: more than just inhibitors of apoptosis proteins. Cell Cycle 2008; 7: 1036-1046. https://doi.org/10.4161/cc.7.8.5783

[20] HU W, TAN C, HE Y, ZHANG G, XU Y et al. Functional miRNAs in breast cancer drug resistance. Onco Targets Ther 2018; 11: 1529-1541. https://doi.org/10.2147/OTT.S152462

[21] KWAK PB, IWASAKI S, TOMARI Y. The microRNA pathway and cancer. Cancer Sci 2010; 101: 2309-2315. https:// doi.org/10.1111/j.1349-7006.2010.01683.x

[22] HE H, JAZDZEWSKI K, LI W, LIYANARACHCHI S, NAGY R et al. The role of microRNA genes in papillary thyroid carcinoma. Proc Natl Acad Sci U S A 2005; 102: 1907519080. https://doi.org/10.1073/pnas.0509603102
[23] SCHETTER AJ, LEUNG SY, SOHN JJ, ZANETTI KA, BOWMAN ED et al. MicroRNA expression profiles associated with prognosis and therapeutic outcome in colon adenocarcinoma. JAMA 2008; 299: 425-436. https://doi. org/10.1001/jama.299.4.425

[24] LU J, GETZ G, MISKA EA, ALVAREZ-SAAVEDRA E, LAMB J et al. MicroRNA expression profiles classify human cancers. Nature 2005; 435: 834-838. https://doi.org/10.1038/ nature 03702

[25] MARKERT EK, LEVINE AJ, VAZQUEZ A. Proliferation and tissue remodeling in cancer: the hallmarks revisited. Cell Death Dis 2012; 3: e397. https://doi.org/10.1038/cddis. 2012.140

[26] VUCIC D, STENNICKE HR, PISABARRO MT, SALVESEN GS, DIXIT VM. ML-IAP, a novel inhibitor of apoptosis that is preferentially expressed in human melanomas. Curr Biol 2000; 10: 1359-1366. https://doi.org/10.1016/s09609822(00)00781-8

[27] LIN JH, DENG G, HUANG Q, MORSER J. KIAP, a novel member of the inhibitor of apoptosis protein family. Biochem Biophys Res Commun 2000; 279: 820-831. https://doi. org/10.1006/bbrc.2000.4027

[28] KASOF GM, GOMES BC. Livin, a Novel Inhibitor of Apoptosis Protein Family Member. J Biol Chem 2001; 276: 3238 3246. https://doi.org/10.1074/jbc.M003670200

[29] SAITO Y, SUZUKI H, TSUGAWA H, NAKAGAWA I, MATSUZAKI J et al. Chromatin remodeling at Alu repeats by epigenetic treatment activates silenced microRNA-512-5p with downregulation of Mcl-1 in human gastric cancer cells. Oncogene 2009; 28: 2738-2744. https://doi.org/10.1038/ onc. 2009.140 